\title{
Antiplatelet agents and perioperative bleeding
}

\section{[Les inbibiteurs plaquettaires et le saignement périopératoire]}

Thomas Lecompte MD, ${ }^{*}$ Jean-François Hardy MD FRCPC ${ }^{\dagger}$

Purpose: To briefly review the risks, in patients presenting for surgery, associated with the available antiplatelet agents, and to present the principles that should guide the evaluation of these risks and how to manage them.

Methods: A narrative review of the current medical literature in English and French.

Main findings: Antiplatelet agents [mainly acetylsalicylic acid, clopidogrel and glycoprotein (GP) Ilb/llla inhibitors] are used increasingly to prevent arterial thrombosis. Clinicians are confronted with the hemorrhagic risk associated with the continuation of antiplatelet agents throughout surgery or, conversely, with the thrombotic risk associated with their discontinuation. Most experts recommend surgery while maintaining acetylsalicylic acid for most vascular procedures and in several additional settings where the bleeding risk has been shown (or is likely) to be low. It is commonly recommended that clopidogrel be stopped five days before surgery to allow replacement of half the platelet pool. This approach has been associated with thrombotic events in patients waiting for urgent myocardial revascularization. In this context, aprotinin may reduce blood losses and transfusion requirements. Withdrawal of the competitive GPIlb/Illa inhibitors at the beginning of surgery will decrease the risk of bleeding, less so for abciximab owing to its avid binding to platelet receptors. Platelets should not be transfused prophylactically, but only to those few patients with abnormal bleeding thought to be related to the persisting effect of antiplatelet therapy.

Conclusions: Unfortunately, data regarding the management of antiplatelet agent-treated patients undergoing surgery, especially non-cardiovascular, are scarce. Further clinical trials must be conducted to guide the clinical management of these patients.
Objectif: Revoir brièvement, chez les patients qui doivent être opérés, les risques associés aux inhibiteurs plaquettaires disponibles et présenter les principes qui devraient guider l'évaluation de ces risques et la façon de les éviter.

Méthode: Une revue descriptive de documents médicaux courants en anglais et en français.

Constatations principales: Les inhibiteurs plaquettaires [surtout l'acide acétylsalicylique, le clopidogrel et les inhibiteurs de la glycoprotéine (GP) Ilb/IIla] sont de plus en plus utilisés pour prévenir la thrombose artérielle. Les cliniciens sont confrontés au risque hémorragique lié à la continuation des inhibiteurs plaquettaires tout au long de l'opération ou, inversement, au risque thrombotique lié à leur interruption. La plupart des experts recommandent la chirurgie tout en maintenant l'acide acétylsalicylique pour la plupart des opérations vasculaires et les autres contextes où le risque d'hémorragie a été prouvé faible, ou pourrait l'être. En général, on recommande d'interrompre le clopidogrel cinq jours avant l'opération pour permettre la régénération du pool plaquettaire. Cette approche a été associée à des incidents thrombotiques chez des patients en attente d'une revascularisation myocardique urgente. Dans ce contexte, l'aprotinine peut réduire les pertes sanguines et les besoins de transfusion. Le retrait des inhibiteurs compétitifs de la GPIIb/IIla, au début de l'opération, diminue le risque de saignement, ce qui est moins le cas de l'abciximab à cause de sa forte liaison aux récepteurs plaquettaires. Les plaquettes doivent être transfusées préventivement, mais seulement aux rares patients dont le saignement anormal semble relié à l'effet persistant du traitement antiplaquettaire.

Conclusion : Malheureusement, les données sont rares concernant le traitement des patients traités aux inhibiteurs plaquettaires qui ne doivent être opérés, surtout en chirurgie non cardiovasculaire. La prise en charge de ces patients nécessite d'autres études cliniques.

From the Service d'Hématologie Biologique, ${ }^{*}$ Centre Hospitalier Universitaire de Nancy, Université Henri Poincaré de Nancy, Nancy, France; and the Centre Hospitalier de l’Université de Montréal, ${ }^{\dagger}$ Montréal, Québec, Canada.

Address correspondence to: Dr. Thomas Lecompte, Hémostase - Service d'Hématologie Biologique, Centre Hospitalier Universitaire de Nancy, 54035 Nancy Cedex, France. E-mail: thomas.lecompte@chu-nancy.fr 
$\mathrm{T}$ HROMBOSIS is defined as the formation of a clot within a vessel or the chambers of the heart. The thrombus consists of various amounts of platelet aggregates and fibrin. Most often arterial thrombosis begins with the rupture of an atherosclerotic plaque, either spontaneous or mechanical (endovascular procedures). Thus, the atherosclerotic core beneath the endothelium is exposed to blood, and platelets adhere to the extracellular matrix, become activated, and recruit new platelets that aggregate. At the same time tissue factor triggers the coagulation cascade. Activated platelets synthesize and release a platelet-activating lipid, thromboxane $\mathrm{A}_{2}$, and release preformed bioactive molecules stored in granules such as adenosine diphosphate and serotonin. They expose receptors for fibrinogen in the form of activated glycoprotein (GP) IIb/IIIa and this constitutes the final common pathway leading to the aggregation of platelets. Ultimately, thrombin generated by the coagulation cascade (i) transforms fibrinogen into fibrin, which polymerizes and stabilizes the thrombus; (ii) potently contributes to the activation of platelets, among many of its effects.

There are several drugs, both old and new, that can prevent, by acting on platelets, a thrombus from developing and/or growing in the coronary and peripheral arterial vasculature. These antiplatelet agents (APA) have different mechanisms and duration of action; they have in common that they cannot be readily reversed by antagonists. Primary hemostasis encompasses events involving platelets and occurring early after the disruption of the continuous endothelial lining and, thus, is instrumental in the protection against clinically significant hemorrhage. Deliberate impairment of primary hemostasis by APA results both in a reduction of thrombotic risk (mainly arterial since platelets are thought to play a key role at this level) and in the alteration of hemostatic competence. As a result, the benefits of APA cannot be separated from the risk of bleeding, which is, however, rarely spontaneous. It is expected that patients receiving antiplatelet therapy before surgery (or any other form of iatrogenic vascular disruption) are at increased risk of bleeding. On the other hand surgery is, early on, associated with changes of the hemostatic system, contributing to the well known increase in the risk of venous thrombosis and also, possibly, resulting in an increased risk of arterial thrombosis, although this is somewhat controversial. Thus a benefit-risk assessment must always be undertaken when APA are administered in such clinical settings. Sometimes this assessment will be easy because the thrombotic risk is overwhelming and the bleeding risk clinically negligible on the whole. Unfortunately, the clinical situation is often more complicated.

This article will briefly review the hemorrhagic risks associated with the available APA. It will present the principles that should guide the evaluation of these risks and how to manage them, based on the current medical literature. In fact, if the use of APA is mostly evidence-based, there limited data regarding the risk of surgical bleeding associated with the use of these agents, and most guidelines do not even broach this important topic. The prospective studies dealing with the possible therapeutic options remain extremely limited.

\section{What are antiplatelet agents?}

These antithrombotic drugs impair platelet function and are used mainly to prevent thrombosis in the arterial vasculature. ${ }^{1,2}$ The current uses of oral APA, presented in Table I, are derived from the recently updated experts' recommendations under the aegis of the American College of Chest Physicians. ${ }^{3}$ The recognized indications were also reviewed by the experts convened under the auspices of the "Société Française d'Anesthésie et de Réanimation" (SFAR; the French society of anesthesiology and intensive care). ${ }^{4}$

The mechanisms of action of the available APA are presented in Table II. There are two groups of drugs: those altering the activation [aspirin and some other nonsteroidal anti-inflammatory drugs (NSAIDs) and thienopyridines] and those inhibiting the aggregation (directed at the GPIIb/IIIa complex) of platelets.

Nonsteroidal anti-inflammatory drugs inhibit one enzyme of the arachidonic acid pathway leading to the production of thromboxane $A_{2}$ when platelets are stimulated, for instance by collagen. Aspirin ${ }^{\mathrm{TM}}$ [acetylsalicylic acid (ASA)] is the sole NSAID that acts irreversibly. It has been shown convincingly that an ASA maintenance dose as low as $0.5 \mathrm{mg} \cdot \mathrm{kg}^{-1} \cdot \mathrm{day}^{-1}$ is enough to bring an inhibition of thromboxane synthesis $>95 \%$ during $24 \mathrm{hr}$, the time elapsed between two doses. To quickly reach such a level of inhibition a loading dose of $>100 \mathrm{mg}$ must be given. Acetylsalicylic acid does not cause a generalized bleeding tendency unless an underlying hemostatic defect is present, or if it is combined with another antithrombotic agent. Nevertheless, its long-term use was shown to be associated with an increased risk of spontaneous intracerebral hemorrhage. ${ }^{5}$ Acetylsalicylic acid impairment of primary hemostasis cannot be separated from its desirable antithrombotic effect at any relevant dose. The NSAIDs indobufen, ibuprofen and flurbiprofen are able to inhibit thromboxane $\mathrm{A}_{2}$ synthesis profoundly but reversibly; this might also be the case with naproxen. 
TABLE I Main recommended uses of oral $\mathrm{APA}^{3}$

\begin{tabular}{|c|c|c|}
\hline Clinical setting & Recommendations & Rating \\
\hline Stable coronary artery disease & $\begin{array}{l}\text { ASA ( } 75-325 \mathrm{mg}) \text {, indefinitely } \\
\text { if ASA contraindicated: clopidogrel }\end{array}$ & $\begin{array}{l}\square \\
\square \\
\square\end{array}$ \\
\hline PCI & $\begin{array}{l}\text { ASA ( } 75-325 \mathrm{mg}) \text { pre- and post PCI } \\
\text { + clopidogrel, loading dose before scheduled PCI }\end{array}$ & - $1 \mathrm{~A}$ \\
\hline & $\begin{array}{l}300 \mathrm{mg} \text { if at least a six-hour delay; } 600 \mathrm{mg} \text { otherwise } \\
\text { duration of therapy with clopidogrel: } \\
\text { PCI in the setting of acute coronary syndrome: nine to } 12 \text { months } \\
\text { Elective PCI and... } \\
\text { - bare stent: at least two weeks } \\
\text { - sirolimus-eluting stent: two to three months } \\
\text { - paclitaxel- eluting stent: six months }\end{array}$ & - $1 \mathrm{~B} / 2 \mathrm{C}$ \\
\hline CABG with a saphenous vein graft & $\begin{array}{l}\text { ASA } 75-162 \mathrm{mg} \text {, given six hours after surgery } \\
\text { (preferred to preoperative administration) } \\
\text { cardiopulmonary bypass and ASA + clopidogrel treatment: } \\
\text { clopidogrel discontinuation five days before }\end{array}$ & - $1 \mathrm{~A}$ \\
\hline Atrial fibrillation & $\begin{array}{l}\text { under the age of } 65 \text { and without risk factors *: ASA } 325 \mathrm{mg} \\
\text { a } 65-75 \mathrm{yr} \text { of age without risk factors *: ASA or warfarin }\end{array}$ & $\begin{array}{l}\text { - } 1 \mathrm{~B} \\
\text { - } 1 \mathrm{~A}\end{array}$ \\
\hline $\begin{array}{l}\text { Secondary prevention when } \\
\text { cerebrovascular disease }\end{array}$ & $\begin{array}{l}\text { APA either ASA } 50-325 \mathrm{mg} \text {, or ASA } 25 \mathrm{mg}+\text { controlled release } \\
\text { dipyridamole } 200 \mathrm{mg} \text { bid, or clopidogrel } \\
\text { (if warfarin not indicated for heart disease) }\end{array}$ & - $1 \mathrm{~A}$ \\
\hline Carotid endarterectomy & $\begin{array}{l}\text { ASA } 75-325 \mathrm{mg} \text {, started preoperatively } \\
\text { (at the expense of an increased bleeding risk) }\end{array}$ & - $1 \mathrm{~A}$ \\
\hline Chronic peripheral arterial disease & $\begin{array}{l}\text { ASA at a dose depending on the presence of coronary artery } \\
\text { disease or } \\
\text { cerebrovascular disease }\end{array}$ & 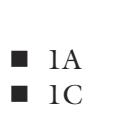 \\
\hline Primary prevention (coronary events) & a intermediate risk: ASA $75-162 \mathrm{mg}$ & - $2 \mathrm{~A}$ \\
\hline $\begin{array}{l}\text { Antiphospholipid antibodies and pregnancy } \\
\text { (the pregnant woman has no history } \\
\text { of thrombosis) }\end{array}$ & $\begin{array}{l}\text { with obstetrical complications **: ASA } 75-325 \mathrm{mg} \text { with } \\
\text { low dose heparin } \\
\text { without obstetrical complications: ASA is one among several options } \\
\text { (including close monitoring) }\end{array}$ & - 2B \\
\hline
\end{tabular}

PCI = percutaneous coronary intervention; $\mathrm{CABG}=$ coronary artery bypass grafting; $\mathrm{ASA}=$ acetylsalicylic acid; $\mathrm{APA}=$ antiplatelet agents . Grade 1 recommendations are strong and indicate that the benefits do, or do not, outweigh the risks, costs and burden. Grade 2 suggests that patient's values may lead to other choices. Level of evidence is indicated by decreasing order as A, B or C. The daily maintenance dose of clopidogrel is $75 \mathrm{mg}$ once a day; recommended daily doses of ASA are variable. $\left({ }^{*}\right)$ established risk factors for stroke in patients with atrial fibrillation (apart from age) include a history of stroke, transient ischemic attack or systemic embolus; left ventricular dysfunction; hypertension; diabetes mellitus. ${ }^{* *}$ ) at least 2 early or 1 late premature termination of pregnancy or history of preeclampsia or intrauterine growth retardation.

The thienopyridines ticlopidine and clopidogrel irreversibly inhibit platelet activation induced by adenosine diphosphate through one of the purinergic receptors present in the platelet membrane. If an effect is sought within hours, a loading dose of 300 or even $600 \mathrm{mg}$ of clopidogrel must be given. Clopidogrel has fewer of the side effects (neutropenia and thrombotic thrombocytopenic purpura) associated with ticlopidine. Acetylsalicylic acid and clopidogrel have two distinct targets and thus their combination inhibits platelet reactivity more powerfully. ${ }^{6}$ This combination has been used increasingly in high-risk patients (especially when threatened by coronary thrombosis) but, in principle, for short periods of time; there is indeed an increase in the risk of spontaneous bleeding. ${ }^{7,8}$

Thus, the two main oral APA used currently differ regarding their target but share two important properties: the irreversible nature of their effect and the absence of an antidote. Full recovery of platelet function requires complete replacement of exposed platelets, since platelets have very low protein synthesis capacity. This takes at most ten days, given the daily turnover of platelets is about $10 \%$. Hemostatic competence does not require, in all likelihood, the intact function of the entire circulating platelet pool, and should recover within a shorter period of time. For instance, it has been reported that, in healthy subjects, primary hemostasis could recover as soon as 48 hr after stopping ASA. ${ }^{9}$ On the other hand, no clinically significant improvement can be expected within the first $24 \mathrm{hr}^{1}$

Glycoprotein IIb/IIIa inhibitors are strong inhibitors of platelet function. They act by blocking the binding of fibrinogen to its receptors (activated 
TABLE II Characteristics of the main antiplatelet medications

\begin{tabular}{|c|c|c|c|c|}
\hline$A P A$ & Mode of action & $\begin{array}{l}\text { PK: elimination } \\
\text { half-life }\end{array}$ & Onset of effect & $\begin{array}{l}\text { Disappearance of effect } \\
\text { after discontinuation }\end{array}$ \\
\hline ASA & irreversible inhibition of COX-1 & approximately $30 \mathrm{~min}$ & rapid if $160 \mathrm{mg}$ dose & platelet life span * \\
\hline Thienopyridines & $\begin{array}{l}\text { irreversible alteration of one } \\
\text { receptor for ADP }\end{array}$ & $\begin{array}{l}\text { irrelevant ( short-lived active } \\
\text { metabolite formed in the liver) }\end{array}$ & $\begin{array}{l}\text { rapid if suitable } \\
\text { loading dose }\end{array}$ & platelet life span ** \\
\hline Dipyridamole & $\begin{array}{l}\text { enhanced adenosine } \\
\text { metabolism *** }\end{array}$ & $\begin{array}{l}\text { depends on whether the } \\
\text { regular or the controlled- } \\
\text { release forms are used }\end{array}$ & related to $\mathrm{PK}$ & $\begin{array}{l}\text { related to } \mathrm{PK} \\
\text { (at most } 12 \mathrm{hr} \text { ) }\end{array}$ \\
\hline Abciximab & $\begin{array}{l}\text { GPIIb/IIIa blockade by very } \\
\text { strong binding }\end{array}$ & $\begin{array}{l}\text { few minutes in plasma, } \\
\text { prolonged (hr) on platelets }\end{array}$ & rapid (bolus) & at least $12 \mathrm{hr} * * * *$ \\
\hline Other, small & GPIIb/IIIa competitive & approximately & rapid (bolus) & a few hours $* * * *$ \\
\hline GPIIb/IIIa inhibitors & antagonism & 1.5-2 hr ***** & & \\
\hline
\end{tabular}

APA $=$ antiplatelet agents; ASA $=$ acetylsalicylic acid; ADP $=$ adenosine diphosphate; $\mathrm{PK}=$ pharmacokinetics. $(*)$ since there is a large excess of production capacity of thromboxane $\mathrm{A}_{2}$, a low amount of fully functional platelets, unexposed to ASA, is probably sufficient. $(* *)$ restoration of hemostatic competence probably does not require complete disappearance of the effect of the drug: five days might suffice (see text). $(* * *)$ the plasma concentration of adenosine, which is a natural (endogenous) platelet inhibitor, would be increased by the impairment of the cellular reuptake processes. $(* * * *)$ as the result of PK, affinity for the glycoprotein (GP)IIb/IIIa complex, and the minimal requirement of half complexes for normal aggregation. $(* * * * *)$ prolonged in case of renal impairment.

GPIIb/IIIa complexes) and are able to prevent platelet aggregation regardless of the trigger. Of note, despite their effectiveness, they are always administered in addition to ASA and heparin (for acute coronary syndromes and during and percutaneous coronary revascularization). Three rapid-acting GPIIb/IIIa inhibitors are available on the market and are administered as an iv bolus followed by a maintenance infusion for $12 \mathrm{hr}$ to a few days. Abciximab is a chimeric (human/murine) IgG Fab fragment directed at the GPIIb/IIIa complex and produces an almost irreversible inhibition due to the very high affinity of the antibody for GPIIb/IIIa. It has been shown that it takes more than $12 \mathrm{hr}$ after stopping an iv infusion for the relative occupancy of GPIIb/IIIa receptors to decrease to about $50 \%{ }^{10}$

Two more recent drugs, eptifibatide and tirofiban, are small synthetic molecules that, administered at a suitable regimen, produce an inhibition roughly comparable to that of abciximab. However, these are competitive inhibitors with short half-lives (two hours or less). When half of the GPIIb/IIIa receptors are again able to bind fibrinogen upon stimulation, full hemostatic competence is, in all likelihood, recovered. ${ }^{11,12}$

\section{What are the risks of hemorrhage?}

Anesthesiologists must be well aware of the hemorrhagic risks associated with APA and be in a position to deal with the various complications that may occur.

The estimated risks of bleeding associated with perioperative antiplatelet therapy are summarized in
Table III, derived from the work of experts convened under the aegis of the SFAR in 2001.4,13 Of note, many interventions could not be discussed in this work because of the lack of clear data. Schematically, the perioperative risk for hemorrhage varies with the type of antiplatelet therapy and the surgical procedure. As a general rule, bleeding increases when the patient receives two or more APA or when antiplatelet therapy is associated with heparin. It is widely thought (and plausible), although unproven, that bleeding is more important with thienopyridines than with NSAIDs. Finally, the sensitivity to APA varies from one individual to another; even if the risk of bleeding is acceptable or slightly elevated in a majority of surgical patients, ${ }^{14}$ in a small number of patients the risk is severe, for reasons that remain unclear. ${ }^{15}$ Most importantly, there is at present no established laboratory test to help identify those patients at risk. ${ }^{4}$ Tonsillectomy, hip arthroplasty, and transurethral prostatectomy tend to bleed more than operations where hemostasis can be more meticulous. For some procedures (e.g., in neurosurgery, ophthalmology - posterior segment of the eye - and otorhinolaryngology), even minimal bleeding can be unacceptable. Generally speaking, while bleeding is rarely life-threatening per se, abnormal bleeding may lengthen hospital stay, increase exposure to blood products (that carry their own hazards), and increase the risk of reoperation and infection (potentially lethal).

On the other hand, arterial thrombosis is a serious complication, more so than venous thrombosis. Within a few days of withdrawal of oral antiplatelet therapy, the risk of thrombosis is the one observed in 
TABLE III Estimated risk of hemorrhage associated with the perioperative use of antiplatelet agents ${ }^{13}$

\begin{tabular}{|c|c|c|c|c|}
\hline $\begin{array}{l}\text { Drugs most often invol } \\
\text { Type of surgery }\end{array}$ & $\begin{array}{l}\text { red in abnormal platelet function in s } \\
\text { Drug therapy }\end{array}$ & $\begin{array}{l}\text { surgical patients } \\
\text { Situation }\end{array}$ & Hemorrbagic risk & Level of evidence \\
\hline \multirow[t]{5}{*}{ Hip surgery } & $\begin{array}{l}\text { Aspirin } 100 \mathrm{mg} \text { with } \\
\text { prophylactic heparin }\end{array}$ & Preoperative & $\begin{array}{l}\text { Increased risk and exposure } \\
\text { to transfusion }\end{array}$ & 1 \\
\hline & $\begin{array}{l}\text { Aspirin and other NSAIDs } \\
\text { (without heparin) }\end{array}$ & Preoperative & $\begin{array}{l}\text { Possible increase in risk and } \\
\text { exposure to transfusion }\end{array}$ & 3 \\
\hline & Aspirin (alone) & Postoperative & $\begin{array}{l}\text { No increased risk or exposure } \\
\text { to transfusion }\end{array}$ & 1 \\
\hline & NSAIDs with prophylactic heparin & Postoperative & $\begin{array}{l}\text { No increased risk or exposure } \\
\text { to transfusion }\end{array}$ & 1 \\
\hline & NSAIDs & Postoperative & $\begin{array}{l}\text { No increased risk or exposure } \\
\text { to transfusion }\end{array}$ & 2 \\
\hline \multirow[t]{2}{*}{ Knee surgery } & Aspirin (alone) & Postoperative & $\begin{array}{l}\text { No increased risk or exposure } \\
\text { to transfusion }\end{array}$ & 1 \\
\hline & NSAIDs & Postoperative & $\begin{array}{l}\text { No increased risk or exposure } \\
\text { to transfusion }\end{array}$ & 2 \\
\hline \multirow[t]{4}{*}{ Cardiac surgery } & Aspirin and other NSAIDs & Preoperative & $\begin{array}{l}\text { Modest increase in risk with } \\
\text { few changes in transfusion } \\
\text { requirements }\end{array}$ & $2-4$ \\
\hline & Abciximab (plus aspirin) & Preoperative & $\begin{array}{l}\text { Possible increase in risk and } \\
\text { exposure to transfusion }\end{array}$ & 3 \\
\hline & Eptifibatide, tirofiban (plus aspirin) & Preoperative & $\begin{array}{l}\text { Possible increase in risk and } \\
\text { exposure to transfusion }\end{array}$ & 3 \\
\hline & Thienopyridine & Preoperative & $\begin{array}{l}\text { Possible increase in risk or } \\
\text { exposure to transfusion }\end{array}$ & 4 \\
\hline Carotid artery surgery & Aspirin & Preoperative & $\begin{array}{l}\text { No increased risk of cervical } \\
\text { hematoma or intracranial bleeding* }\end{array}$ & 3 \\
\hline Tonsillectomy & NSAIDs including aspirin & Pre- or postoperative & $\begin{array}{l}\text { Possible increased risk and revision } \\
\text { procedures for hemostasis }\end{array}$ & $1-3$ \\
\hline \multicolumn{5}{|l|}{ Ophthalmology } \\
\hline $\begin{array}{l}\text { Anterior chamber, } \\
\text { avascular structures } \\
\text { (lens, cornea) }\end{array}$ & Aspirin & Preoperative & Small increase in risk & 2 \\
\hline Strabismus surgery & NSAIDs & Postoperative & No increased risk & 2 \\
\hline Intracranial surgery & All platelet function inhibition & Preoperative & Increased risk & $3-4$ \\
\hline \multirow[t]{2}{*}{$\begin{array}{l}\text { Prostate via } \\
\text { abdominal approach }\end{array}$} & NSAIDs & Postoperative & $\begin{array}{l}\text { Low increase in risk with no } \\
\text { increase in transfusion requirements }\end{array}$ & 2 \\
\hline & Aspirin & Preoperative & $\begin{array}{l}\text { Possible increase in risk and } \\
\text { transfusion requirements }\end{array}$ & 3 \\
\hline \multirow[t]{2}{*}{$\begin{array}{l}\text { Transurethral } \\
\text { prostatic resection }\end{array}$} & Ticlopidine & Pre- or postoperative & $\begin{array}{l}\text { Increased risk and transfusion } \\
\text { requirements }\end{array}$ & 2 \\
\hline & Aspirin and other NSAIDs & Preoperative & Contradictory findings & $2-3$ \\
\hline $\begin{array}{l}\text { Gastrointestinal and } \\
\text { general surgery }\end{array}$ & $\begin{array}{l}\text { NSAIDs if patient is less } \\
\text { than } 75 \mathrm{yr} \text { old }\end{array}$ & $\begin{array}{l}\text { Postoperative by } \\
\text { less than } 5 \text { days }\end{array}$ & $\begin{array}{l}\text { No increased risk or revision } \\
\text { procedures for hemostasis }\end{array}$ & 3 \\
\hline General & Thienopyridines & Preoperative & High increase in risk & $3-4$ \\
\hline Vaginal delivery & Aspirin & Before & $\begin{array}{l}\text { No increase in the incidence or } \\
\text { severity of hemorrhage } \\
\text { during delivery }\end{array}$ & 2 \\
\hline Cesarean section & NSAIDs & $?$ & No increased risk & 2 \\
\hline
\end{tabular}

${ }^{*}$ For carotid surgery, the only randomized placebo-controlled trial studied the pre- and postoperative administration (one single dose) of low-dose aspirin $(75 \mathrm{mg}$ ), and preoperative anticoagulation with heparin was neutralized by postoperative administration of protamine. Reproduced with permission from: Samama CM, Djoudi R, Lecompte T, Nathan-Denizot N, Schved JF; Agence Française de Sécurité Sanitaire des Produits de Santé (AFSSaPS) 2003. Perioperative platelet transfusion: recommendations of the Agence Française de Sécurité Sanitaire des Produits de Santé (AFSSaPS) 2003: Can J Anesth 2005; 52: 30-7. 
the inactive treatment arm of clinical trials, and might be increased because of enhanced platelet reactivity in the postoperative period. ${ }^{16}$ In contrast, the possibility of a rebound phenomenon remains questionable.

\section{How should we manage APA in practice?}

The main APA will be reviewed in succession, mentioning those aspects specific to cardiac surgery (with cardiopulmonary bypass) as appropriate. Subsequently, selected clinical settings will be discussed briefly.

The assessment of the bleeding risk if the APA is continued and of the thrombotic risk if the APA is withheld leads, schematically, to two options with their associated issues:

(i) The APA is withheld (and resumed as soon as possible): how can the period when there is no protection against thrombosis be kept to a minimum?

(ii) The APA is maintained: how can bleeding be minimized and how should active, life-threatening bleeding be managed?

\section{Acetylsalicylic acid}

The expert panel of the SFAR concluded that: "In patients presenting with either coronary or cerebrovascular disease, long-term treatment with aspirin is recommended, and should not be stopped in the perioperative period unless the risk of hemorrhagic complications related to a specific procedure appears to be greater than the increase in the cardiovascular (thrombotic) risk (especially of an acute coronary syndrome) from withholding the APA." 4

Undeniably, stopping ASA in a patient with coronary disease may increase the risk of a thrombotic event. ${ }^{17}$ Conversely, continuing ASA in patients undergoing infrainguinal vascular surgery appeared to decrease perioperative mortality and prolong life, which questions the systematic withdrawal of ASA preoperatively. ${ }^{18}$ The number of major vascular events avoided with ASA over a given period of time is quite well established, ${ }^{1}$ and thus the minimal number of events that will occur because of ASA discontinuation (assuming the disappearance of the protective effect within $48 \mathrm{hr}$ ) can be calculated for each main group of patients at risk of coronary thrombosis. These are composed of patients who receive ASA for, by increasing order of thrombotic risk, primary prevention, chronic stable angina, prior myocardial infarction, and recent (within three months) unstable angina.

In the meta-analysis mentioned previously, the section devoted to APA administered to preserve vessel patency after vascular procedures suggests that their preoperative use is associated with increased bleeding, as compared to their administration in the postoperative period exclusively. ${ }^{5}$ One of the most important and recent trials with deliberate perioperative ASA exposure is the Pulmonary Embolism Prevention trial. ${ }^{19}$ In the active arm, the administration of ASA (160 mg.qid) was started before the procedure in an attempt to prevent venous thromboembolic events after hip surgery. Although it did not increase perioperative mortality secondary to hemorrhagic complications, the authors found an increase in the number of gastrointestinal bleeding events and a decrease in postoperative hemoglobin (average of $2 \mathrm{~g} \cdot \mathrm{L}^{-1}$ ), as well as an increased need for blood transfusions $(53 \mathrm{~mL}$ on average); this modest level of hemorrhagic complications tended to occur in patients who were also receiving $s c$ heparin.

In cardiac surgery, the importance of the hemorrhagic risk associated with ASA remains controversial. In an extensive review of 50 articles covering > 10,000 patients undergoing cardiac operations in 70 hospitals, Bélisle et al. concluded that bleeding was increased by only $300 \mathrm{~mL}$ on average. This modest increase in bleeding did not explain the great variation in transfusion rates from one hospital to another. ${ }^{14}$

This is one of the rare settings, though, where the effect of preoperative administration of ASA followed by long-term postoperative therapy was formally compared to postoperative therapy alone. It was reported that a single $325 \mathrm{mg}$ dose of ASA given $12 \mathrm{hr}$ before surgery was not associated with any benefit regarding the occlusion of venous aortocoronary grafts while bleeding was increased, albeit modestly. ${ }^{20}$

In practical terms, since it appears impossible to predict the hemorrhagic risk in a given patient, it seems reasonable to wait until the patient is separated from extracorporeal circulation, heparin is neutralized, and surgical hemostasis is achieved before transfusing exogenous platelets, as needed. The prophylactic administration of aprotinin has been clearly shown to be effective in such circumstances. ${ }^{21}$

\section{The thienopyridines (ticlodipine and clopidogrel)}

Very few studies have examined specifically the perioperative risks of hemorrhage related to the use of thienopyridines. Because of their more potent effect on platelet behaviour, as compared to ASA, and the absence of clinical research specifically addressing the risk of bleeding despite the very large number of patients recruited in various clinical trials, most experts are reluctant to advise their continuation before surgery, in contrast to ASA.

The incidence of thrombotic complications and/or hemorrhagic events in patients undergoing surgery 
soon after deployment of a coronary endovascular bare stent is prohibitive. ${ }^{22}$ These patients must receive APA, consisting of a combination of ASA and a thienopyridine, for two to four weeks after angioplasty. Stopping the antiplatelet medication increases the risk of coronary thrombosis considerably, but continuing the medication is associated with an increased risk of both hemorrhage and the need for blood transfusions. ${ }^{22}$ As a result, elective surgery should be avoided for a period of one to three months following placement of a bare stent. ${ }^{4}$ On the other hand, if coronary angioplasty is deemed necessary before surgery, the deployment of a stent should be avoided, even more so a drug-eluting one.

Recently, the risk of bleeding associated with clopidogrel combined with ASA during coronary artery bypass grafting (CABG) was assessed within the CURE trial. The authors found that bleeding was clearly increased in those patients who continued to receive the study drug, as opposed to those in whom, as recommended, the treatment could be discontinued for at least five days prior to surgery (all patients remained on ASA). ${ }^{7}$ This explains the current recommendation of withholding clopidogrel therapy at least five days before planned CABG. These findings of an increased hemorrhagic risk of patients exposed to clopidogrel, in addition to aspirin, prior to CABG surgery were corroborated by a recent database review of 2,359 patients. ${ }^{23}$

However, quite recently, aprotinin was shown to normalize bleeding and the need for transfusion in patients requiring urgent cardiac surgery while treated with clopidogrel. ${ }^{24-26}$ In fact, interrupting clopidogrel five days prior to surgery led to major adverse cardiac events (myocardial infarction) $)^{24}$ and should probably be avoided in these unstable patients. It remains to be shown if this approach can or should be used systematically in patients presenting for elective surgery while treated with clopidogrel.

If clopidogrel therapy is to be resumed postoperatively, then a loading dose should be considered to achieve the desirable effect within hours, not days, in order to minimize the period during which the patient is not protected against thrombosis.

\section{Glycoprotein IIb/IIIa inbibitors}

Patients receiving GPIIb/IIIa inhibitors are also receiving ASA and heparin, and even clopidogrel in the case of coronary stenting. As mentioned earlier, abciximab produces a long lasting (> $12 \mathrm{hr}$ ) antiplatelet effect. ${ }^{1}$ During the course of the main studies evaluating the efficacy of abciximab in decreasing thrombotic complications after coronary angioplasty, some patients required urgent myocardial revascularization. In the EPIC study, the need for transfusions in operated patients treated with abciximab was the same as in those treated with placebo; the incidence of major bleeding was high (approximately 70\%) in both groups. ${ }^{27}$ The combined results for operated patients in both the EPILOG and EPISTENT studies are essentially the same, except for an increased need for platelet transfusions. ${ }^{28}$ It is very important to note that most patients were taken to the operating room $>12 \mathrm{hr}$ after abciximab was stopped. Gammie et al. reported a marked increase in the hemorrhagic risk and in the transfusion needs of patients operated on $<12 \mathrm{hr}$ following the interruption of abciximab. ${ }^{29}$ Transfusion of platelets might help to reduce both postoperative bleeding and the need for transfusions of red blood cells and fresh frozen plasma. Any unbound medication in the plasma disappears rapidly after stopping the drug infusion, and the remaining abciximab binds equally to native and exogenous platelets. This decreases the occupancy rate of receptors, so that platelet function normalizes. ${ }^{11,12,30}$ Systematic transfusion of platelets is not recommended, and should only be envisaged after hemostasis has been assessed after the neutralization of heparin with protamine.

Regarding the other GPIIb/IIIa inhibitors, their half-lives are short, and their inhibitory effects are competitive in nature. Thus, stopping the infusion just before the operation will allow the drug effect to disappear when the procedure is completed, i.e., when hemostasis is required. On the other hand, transfusion of platelets when there is a large amount of drug in plasma will most likely inhibit platelet effect, rendering the transfusion useless.

Glycoprotein IIb/IIIa inhibitors have, in essence, been studied only in patients undergoing cardiac surgery. Until further data become available, the recommendations for patients treated with GPIIb/IIIa inhibitors about to undergo CABG should apply also to similar patients about to undergo noncardiac surgery.

\section{Miscellaneous conditions}

\section{Particular thrombotic Disorders}

The mere presence of the so-called antiphospholipid antibodies is no longer considered as justifying aggressive antithrombotic therapy, except in selected cases. ${ }^{3}$ A prolongation of clotting tests such as the activated partial thromboplastin time, due to the presence of these antibodies (the so-called lupus anticoagulants), does not indicate an increased bleeding risk, and does not contraindicate antithrombotic therapy.

In a patient with a known myeloproliferative disorder such as essential thrombocythemia who is receiv- 
ing APA and scheduled for surgery, it is beneficial to start myelotoxic therapy before surgery in order to decrease both thrombotic and bleeding risks through normalization of the platelet count (additionally, this might allow interruption of ASA therapy).

\section{PATIENTS ON COMBINED THERAPY}

The spontaneous and vascular-trauma related risks of bleeding are increased when two drugs are combined, compared to ASA monotherapy. One exception is the combination of ASA and dipyridamole. Patients receiving the latter drug combination should be be converted to ASA or anticoagulant alone before surgery, if possible.

Acetylsalicylic acid + dipyridamole (bid) for cerebrovascular disease: dipyridamole does not act beyond its presence in blood, which lasts $12 \mathrm{hr}$ for the controlled release formulation which is associated with a low dose of ASA $(25 \mathrm{mg})$.

Acetylsalicylic acid + clopidogrel after a recent acute coronary event: if the patient received a stent, see the recommendations formulated previously; in the absence of stenting, surgery should also be postponed for more than one month, and at least one APA (most often ASA) should be continued perioperatively.

Acetylsalicylic acid + warfarin for a combined thrombotic risk, e.g., within arteries (atherosclerosis) and the left atrium (atrial fibrillation): try to determine which is the main risk, and select the corresponding antithrombotic therapy to be maintained (see article on the perioperative management of vitamin $\mathrm{K}$ antagonists).

How SHOULD ONE DEAL WITH THE CONCOMITANT RISK OF VENOUS THROMBOSIS?

Venous thromboembolism is rarely as severe as arterial thrombosis. The risk of venous thrombosis associated with surgery is well established and heparins have been shown to reduce it more effectively than ASA, which has nevertheless some protective effect. ${ }^{19,31}$ On the other hand, heparin therapy without aspirin has not been demonstrated to be an active treatment against arterial thrombosis. Finally, the addition of heparin to ASA is known to increase the risk of bleeding. Hence the dilemma: should we continue ASA alone, add prophylactic heparin, or should we use heparin alone? More data are urgently needed to answer these questions.

\section{Platelet transfusions}

There is limited high grade evidence that platelet transfusions are efficacious in case of active bleeding, but the approach is logical, and platelets remain the
TABLE IV Non specific methods to decrease perioperative blood losses ${ }^{4}$

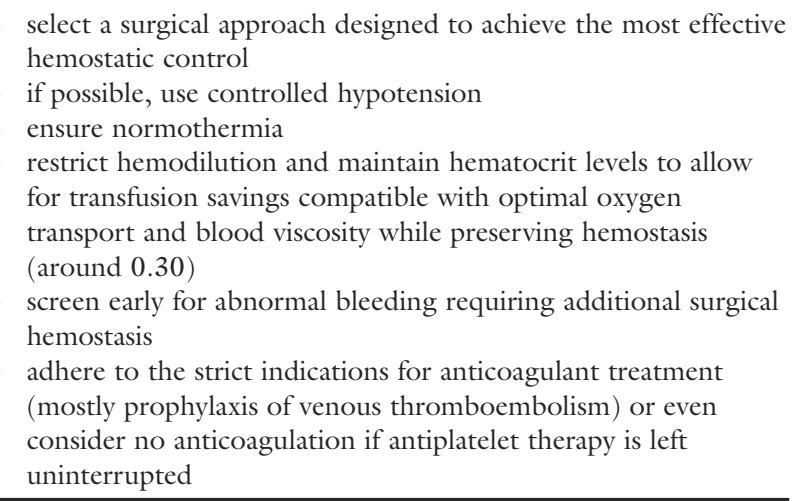

last resort in case of life-threatening hemorrhage. The novel hemostatic agent, recombinant activated factor VII, has not been studied in this setting. The dosage of platelets is empirical: 5 to $7 \times 10^{10}$ platelets per $7 \mathrm{~kg}$ of body weight. ${ }^{4} \mathrm{~A}$ higher dosage might be required to allow complete redistribution of abciximab to the exogenous platelets, with the aim of having $<50 \%$ of the GPIIb/IIIa complexes occupied by the drug - see above. $^{11}$

\section{Summary and conclusions}

(i) For elective surgery, the practice of withdrawing all forms of oral APA has been challenged in the past few years because of the fear of an unopposed and even increased risk of ischemic events. More specifically, in patients with a recent (less than one month) arterial event and receiving two APA, it is highly advisable to postpone surgery until ASA can be given as the sole but uninterrupted therapy; if coronary stenting has been performed, the window period ends when the rate of late recurrence of ischemia starts to rise again. Most experts now recommend surgery while maintaining ASA therapy for most vascular procedures and operations where the bleeding risk is low, provided that other risk factors for bleeding are kept under control (Table IV), a suitable anesthetic is administered, that means to stop abnormal bleeding are readily available, and the patient is informed of, and accepts the risks involved.

The SFAR concludes that "aspirin can be discontinued in the perioperative period only when, compared with the benefits, the specific hemorrhagic risk inherent to the intervention is definitely greater than the cardiovascular risk associated with discontinuation". ${ }^{4}$ On the other hand, discontinuation will facilitate effi- 
cient hemostasis and allow prompt and safe resumption of antiplatelet therapy in the early postoperative period, when it is probably most needed. When deemed appropriate, preoperative discontinuation can be minimized, taking into account the mode of action (reversible or not, and if reversible, the elimination half-life) and thus the variable duration of action of the different APA. Replacing long-acting molecules by medications with a short half-life and a reversible mechanism of action, e.g., indobufen or flurbiprofen, NSAIDs that are inhibitors of platelet thromboxane $\mathrm{A}_{2}$ synthesis, ${ }^{1}$ will allow the controlled interruption of antiplatelet therapy in the immediate perioperative period and its resumption as soon as the hemorrhagic risk appears reasonable (within six hours). This option has not been validated clinically, though it appears reasonable.

(ii) In the context of emergency surgery, two settings must be distinguished. In patients with acute coronary events and requiring $\mathrm{CABG}$, withdrawal of the competitive inhibitors of the GPIIb/IIIa receptor at the beginning of surgery will permit a decrease in the risk of bleeding, less so for abciximab owing to its avid binding to platelet receptors. Regarding outpatients receiving an irreversible oral APA (ASA or clopidogrel), no significant improvement can be expected within the first $24 \mathrm{hr}$. The prophylactic use of platelet transfusions is not recommended. Rather, transfusions should be given only as needed to those few patients with abnormal bleeding thought to be related, at least in part, to the persisting effect of antiplatelet therapy.

In practice, the risk of surgical bleeding associated with ASA therapy can be considered to be much lower than the risk of postponing urgent surgery, while leaving a patient without any protection against thrombosis, especially if recent revascularization or recurrent ischemia have occurred.

In conclusion, APA are used increasingly to prevent arterial thrombosis. Unfortunately, data regarding the management of APA treated patients undergoing surgery, especially non-cardiovascular procedures, are scarce. Further clinical trials are required to guide the clinical management of these patients.

\section{References}

1 Patrono C, Bachmann F, Baigent C, et al. Expert consensus document on the use of antiplatelet agents. The task force on the use of antiplatelet agents in patients with atherosclerotic cardiovascular disease of the European society of cardiology. Eur Heart J 2004; 25 : 166-81.

2 Patrono C, Coller B, FitzGerald GA, Hirsh J, Roth G. Platelet-active drugs: the relationships among dose, effectiveness, and side effects: the Seventh ACCP Conference on Antithrombotic and Thrombolytic Therapy. Chest 2004; 126: 234S-64.

3 Anonymous. The Seventh ACCP Conference on Antithrombotic and Thrombolytic Therapy: EvidenceBased Guidelines. Chest 2004; 126: 163S-696S.

4 Samama CM, Bastien O, Forestier F, et al. Antiplatelet agents in the perioperative period: expert recommendations of the French Society of Anesthesiology and Intensive Care (SFAR) 2001--summary statement. Can J Anesth 2002; 49: S26-35.

5 Antithrombotic Trialists Collabroation. Collaborative meta-analysis of randomised trials of antiplatelet therapy for prevention of death, myocardial infarction, and stroke in high risk patients. BMJ 2002; 324: 71-86.

6 Lecompte TP, Lecrubier C, Bouloux C, et al. Antiplatelet effects of the addition of the addition of acetylsalicylic acid $40 \mathrm{mg}$ to ticlopidine in human healthy volunteers. Clin Appl Thromb Hemost 1997; 3: 245-50.

7 Yusuf S, Zhao F, Mehta SR, Chrolavicius S, Tognoni G, Fox KK; Clopidogrel in Unstable Angina to Prevent Recurrent Events Trial Investigators. Effects of clopidogrel in addition to aspirin in patients with acute coronary syndromes without ST-segment elevation. N Engl J Med 2001; 345: 494-502.

8 Steinhubl SR, Berger PB, Mann JT 3 ${ }^{\text {rd }}$, et al.; CREDO Investigators. Clopidogrel for the Reduction of Events During Observation. Early and sustained dual oral antiplatelet therapy following percutaneous coronary intervention: a randomized controlled trial. JAMA 2002; 288: 2411-20.

9 Sonksen JR, Kong KL, Holder R. Magnitude and time course of impaired primary haemostasis after stopping chronic low and medium dose aspirin in healthy volunteers. Br J Anaesth 1999; 82: 360-5.

10 Tcheng JE, Ellis SG, George BS, et al. Pharmacodynamics of chimeric glycoprotein IIb/IIIa integrin antiplatelet antibody Fab 7E3 in high-risk coronary angioplasty. Circulation 1994; 90: 1757-64.

11 Coller BS. Pharmacologic and transfusion strategies to alter function and production: c7E3 (Abciximab). Blood 1995; Educational Supplement: 45-7.

12 Coller BS. Therapeutic results with abciximab, an antagonist of the platelet GPIIb/IIIa $(\alpha I I b / \beta 3)$ receptor. Blood 2000; Educational Supplement: 401-8.

13 Samama CM, Djoudi R, Lecompte T, Nathan-Denizot N, Schved JF; Agence Française de Sécurité Sanitaire des Produits de Santé (AFSSaPS) 2003. Perioperative platelet transfusion: recommendations of the Agence Française de Sécurité Sanitaire des Produits de Santé (AFSSaPS) 2003: Can J Anesth 2005; 52: 30-7.

14 Belisle S, Hardy JF. Hemorrhage and the use of blood products after adult cardiac operations: myths and 
realities. Ann Thorac Surg 1996; 62: 1908-17.

15 Ferraris VA, Ferraris SP. 1988: Preoperative aspirin ingestion increases operative blood loss after coronary artery bypass grafting. Updated in 1995. Ann Thorac Surg 1995; 59: 1036-7.

16 Samama CM, Thiry D, Elalamy I, et al. Perioperative activation of hemostasis in vascular surgery patients. Anesthesiology 2001; 94: 74-8.

17 Collet JP, Himbet F, Steg PG. Myocardial infarction after aspirin cessation in stable coronary artery disease patients. Int J Cardiol 2000; 76: 257-8.

18 Neilipovitz DT, Bryson GL, Nichol G. The effect of perioperative aspirin therapy in peripheral vascular surgery: a decision analysis. Anesth Analg 2001; 93 : 573-80.

19 Anonymous. Prevention of pulmonary embolism and deep vein thrombosis with low dose aspirin: Pulmonary Embolism Prevention (PEP) trial. Lancet 2000; 355 : 1295-302.

20 Goldman S, Copeland J, Moritz T, et al. Starting aspirin therapy after operation. Effects on early graft patency. Department of Veterans Affairs Cooperative Study Group. Circulation 1991; 84: 520-6.

21 Levi $M$, Crombeecke ME, de Jonge E, et al. Pharmacological strategies to decrease excessive blood loss in cardiac surgery: a meta-analysis of clinically relevant endpoints. Lancet 1999; 354: 1940-7.

22 Kaluza GL, Joseph J, Lee JR, Raizner ME, Raizner AE. Catastrophic outcomes of noncardiac surgery soon after coronary stenting. J Am Coll Cardiol 2000; 35: 1288-94.

23 Kapetanakis EI, Medlam DA, Boyce SW, et al. Clopidogrel administration prior to coronary artery bypass grafting surgery: the cardiologist's panacea or the surgeon's headache? Eur Heart J 2005; 26: 57683.

24 Akowuah E, Shrivastava V, Jamnadas B, et al. Comparison of two strategies for the management of antiplatelet therapy during urgent surgery. Ann Thorac Surg 2005; 80: 149-52.

25 Lindvall G, Sartipy U, van der Linden J. Aprotinin reduces bleeding and blood product use in patients treated with clopidogrel before coronary artery bypass grafting. Ann Thorac Surg 2005; 80: 922-7.

26 van der Linden J, Lindvall G, Sartipy U. Aprotinin decreases postoperative bleeding and number of transfusions in patients on clopidogrel undergoing coronary artery bypass graft surgery: a double-blind, placebocontrolled, randomized clinical trial. Circulation 2005; 112(Suppl 9): I276-80.

27 Boehrer JD, Kereiakes DJ, Navetta FI, Califf RM, Topol $E J$. Effects of profound platelet inhibition with c7E3 before coronary angioplasty on complications of coro- nary bypass surgery. EPIC Investigators. Evaluation Prevention of Ischemic Complications. Am J Cardiol 1994; 74: 1166-70.

28 Lincoff AM, LeNarz LA, Despotis GJ, et al. Abciximab and bleeding during coronary surgery: results from the EPILOG and EPISTENT trials. Improve Longterm Outcome with abciximab GP IIb/IIIa blockade. Evaluation of Platelet IIb/IIIa Inhibition in STENTing. Ann Thorac Surg 2000; 70: 516-26.

29 Gammie JS, Zenati M, Kormos RL, et al. Abciximab and excessive bleeding in patients undergoing emergency cardiac operations. Ann Thorac Surg 1998; 65: 465-9.

30 Coller BS. GPIIb/IIIa antagonists: pathophysiologic and therapeutic insights from studies of c7E3 Fab. Thromb Haemost 1997; 78: 730-5.

31 Anonymous. Collaborative overview of randomised trials of antiplatelet therapy--III: reduction in venous thrombosis and pulmonary embolism by antiplatelet prophylaxis among surgical and medical patients. Antiplatelet Trialists' Collaboration. BMJ 1994; 308: 235-46. 